\title{
In-vitro antibiofilm activity of chlorhexidine digluconate on polylactide-based and collagen-based membranes
}

\author{
Jan-Luca Rudolf', Corina Moser ${ }^{2}$, Anton Sculean $^{1}$ and Sigrun Eick ${ }^{1 *}$ (i)
}

\begin{abstract}
Background: In Guided Tissue Regeneration (GTR), barrier membranes are used to allow selective cell populations to multiply and to promote periodontal regeneration. A frequent complication is membrane exposure to the oral cavity followed by bacterial colonization. The purpose of this in-vitro-study was to elucidate, if rinsing with a chlorhexidine digluconate solution (CHX) prevents bacterial adhesion, and whether it interferes with attachment of periodontal ligament (PDL) fibroblasts and epithelial cells to membrane surfaces.
\end{abstract}

Methods: Firstly, two bioresorbable membranes (polylactide-based and collagen-based) were dipped into 0.06\% $\mathrm{CHX}$ and $0.12 \% \mathrm{CHX}$, before biofilms (2-species representing periodontal health, 6-species representing a periodontitis) were formed for $2 \mathrm{~h}$ and $8 \mathrm{~h}$. Subsequently, colony forming units (cfu) were counted. Secondly, the membranes were treated with $\mathrm{CHX}$ and inoculated in bacteria suspension two-time per day for $3 \mathrm{~d}$ before cfu were determined. In additional series, the influence of $\mathrm{CHX}$ and bacterial lysates on attachment of epithelial cells and PDL fibroblasts was determined. Parameter-free tests were applied for statistical analysis.

Results: Cfu in "healthy" biofilms did not differ between the two membranes, more cfu were counted in "periodontitis" biofilm on collagen than on polylactide membranes. One-time dipping of membranes into CHX solutions did not markedly influence the cfu counts of both biofilms on polylactide membrane; those on collagenbased membrane were significantly reduced with being $0.12 \% \mathrm{CHX}$ more active than $0.06 \% \mathrm{CHX}$. More-fold CHX dipping of membranes reduced concentration-dependent the cfu counts of both biofilms on both membranes. In general, the number of attached gingival epithelial cells and PDL fibroblasts was higher on collagen than on polylactide membrane. Lysates of the periodontopathogenic bacteria inhibited attachment of PDL fibroblasts to membranes. CHX decreased in a concentration-dependend manner the number of attached gingival epithelial cells and PDL fibroblasts.

Conclusions: The present in-vitro results appear to indicate that membranes in GTR should only be used when bacteria being associated with periodontal disease have been eliminated. An exposure of the membrane should be avoided. Rinsing with $\mathrm{CHX}$ may prevent or at least retard bacterial colonization on membrane exposed to the oral activity. However, a certain negative effect on wound healing cannot be excluded.

Keywords: Guided tissue regeneration, Bioresorbable membrane, Antiseptic, Bacterial colonization, Periodontal ligament fibroblasts, Gingival epithelial cells

\footnotetext{
* Correspondence: sigrun.eick@zmk.unibe.ch

${ }^{1}$ Department of Periodontology, School of Dental Medicine, University of

Bern, Bern, Switzerland

Full list of author information is available at the end of the article
}

(c) The Author(s). 2019 Open Access This article is distributed under the terms of the Creative Commons Attribution 4.0 International License (http://creativecommons.org/licenses/by/4.0/), which permits unrestricted use, distribution, and reproduction in any medium, provided you give appropriate credit to the original author(s) and the source, provide a link to the Creative Commons license, and indicate if changes were made. The Creative Commons Public Domain Dedication waiver (http://creativecommons.org/publicdomain/zero/1.0/) applies to the data made available in this article, unless otherwise stated. 


\section{Background}

Guided Tissue Regeneration (GTR) is an established surgical technique in reconstructive periodontal surgery. Barrier membranes are used to mechanically isolate the treated defects in order to prevent proliferation of epithelial and connective tissue cells into the wound [1, 2]. Thus, they support proliferation of periodontal ligament and bone cells onto the root surfaces and into the defect which leads ultimately to formation of connective tissue attachment (i.e. new cementum with perpendicularly inserting collagen fibers) and bone [1, 2]. Resorbable membranes have been developed to avoid surgical removal of the membrane, thus minimizing the risk of damaging the newly formed tissues. Animal and humanderived collagen-based membranes and polyester-based membranes consisting of polylactic acid and its copolymers are routinely used in the clinical setting [1]. The membranes should not induce any inflammatory reaction and must present a degradation profile that matches with new tissue formation [1]. As recently reported in a systemic review, treatment of intrabony defects with GTR using collagen membranes results in a mean of $1.58 \mathrm{~mm}$ higher clinical attachment level gain compared with open flap debridement alone [3].

Complications which might occur after surgical procedure are exposure of the membrane, bacterial contamination and infection [4]. Exposure of a membrane is a frequently reported complication following regenerative periodontal surgery [5]. Following exposure to the oral cavity, bacterial colonization immediately occurs implying an increased risk of infection, thus jeopardizing the regeneration process and the final clinical outcomes [6-8].

Bacteria associated with periodontal disease may interfere with wound healing following GTR. If the oral cavity of a patient is colonized by these bacteria, the same species can be also found in high percentages at the sites, where surgery was performed [9]. It has been shown that bacteria attached to membranes inhibit the attachment of periodontal ligament fibroblasts [10]. In vitro bacteria adhere in high numbers to membranes, at which adhesion was significantly higher to collagen membranes compared to non-resorbable PTFE-based barriers [11].

In order to decrease the bacterial load, chlorhexidine digluconate solutions are usually applied post-surgically, but very rarely the effect of chlorhexidine on bacterial contamination of membranes was investigated. Chen et al. [10] found an inhibition of Aggregatibacter actinomycetemcomitans adhesion, but also a decreased viability of $50 \%$ of PDL fibroblasts in the presence of $0.0015 \%$ $\mathrm{CHX}$. Clinically, the application of a $\mathrm{CHX}$ chip was beneficial in periodontal regeneration [12]. In another study, biofilm accumulation was followed in volunteers on removable membranes after rinsing with $\mathrm{CHX}$ solution for $4 \mathrm{~h}$ and $24 \mathrm{~h}$. The results showed an inhibitory effect of CHX but also an influence of the membrane material [13]. In a similar experimental design, but with a follow-up of 4 weeks, no effect of $\mathrm{CHX}$ on preventing or retarding bacterial adhesion was seen [14].

The purpose of the present in-vitro-study was to investigate, if rinsing with a chlorhexidine digluconate solution (CHX) may prevent bacterial adhesion and biofilm formation on bioresorbable synthetic and collagenbased membranes using two different biofilms (i.e. one representing periodontal health and the other representing periodontal disease). Furthermore, the question was to be answered whether rinsing with a chlorhexidine digluconate solution, may interfere with the attachment of periodontal ligament (PDL) fibroblasts or epithelial cells to the membranes.

\section{Material and methods \\ Membranes}

Two bioresorbable membranes were included, one consisting of polylactide and blended with citric acid ester (GUIDOR ${ }^{\bullet}$ Bioresorbable Matrix Barrier; Sunstar Suisse SA; Etoy, Switzerland), and the other was a membrane consisting of porcine pericardium collagen (Jason ${ }^{\oplus}$, kindly provided by botiss materials $\mathrm{GmbH}$, Zossen, Germany).

From these membranes, test specimens with a size of $5 \times 5 \mathrm{~mm}$ were prepared.

\section{Chlorhexidine digluconate solution}

$\mathrm{CHX}$ without additives were obtained from the pharmacy of the University hospital Bern and prepared as a $0.12 \%$ (CHX0.12), $0.06 \%$ (CHX0.06), and $0.015 \%$ (CHX0.015) CHX.

\section{Microorganisms}

The microorganisms Streptococcus gordonii ATCC 10558, Actinomyces naeslundii ATCC 12104, Porphyromonas gingivalis ATCC 33277, Tannerella forsythia ATCC 43037, Fusobacterium nucleatum ATCC 25586, and Parvimonas micra ATCC 33270. were included in the assays. S. gordonii and A. naeslundii represent early colonizers, whereas $P$. gingivalis, $T$. forsythia, F. nucleatum and $P$. micra are known to be clearly associated with periodontal diseases. Prior to the experiments, all strains were precultivated on Schaedler agar plates (Oxoid, Basingstoke, UK) with 5\% sheep blood (JP. Mischler, Switzerland) overnight in an anaerobic atmosphere or with $5 \% \mathrm{CO}_{2}$ (S. gordonii ATCC 10558). Bacteria concentration was adjusted to OD600 nm $=0.5$ in $0.9 \% \mathrm{v} / \mathrm{w} \mathrm{NaCl}$ (equivalent to $10^{9}$ bacteria $/ \mathrm{ml}$ ). Then mixed suspension was prepared by mixing 1 part $S$. 
gordonii with 2 parts $A$. naeslundii (and each 4 parts of the other species for six-species mixture).

\section{Cells}

Human PDL fibroblasts were anonymously collected from periodontally healthy patients during regular orthodontic treatment following written informed consent. This procedure is approved by the Ethics Committee of the University of Bern. Human PDL fibroblasts were placed in T-25 cell culture flasks containing DMEM (Life Technologies / Invitrogen, Paisley, UK) with $10 \%$ foetal calf serum (FCS; Life Technologies / Invitrogen) to grow to confluency. At the starting of the experiments, the fibroblasts were always in the 4 th -6 th passage.

The telomerase-inactivated gingival keratinocytes (TIGK) kindly provided by R. Lamont, University of Louisville, KY, USA [15]) were maintained in cell cultivation media (Keratinocyte Growth Medium, KGMGold, Lonza, Basel, Switzerland). Confluent monolayers of PDL fibroblasts and TIGK cells were detached by trypsin / EDTA and the amount of epithelial cells was adjusted to about $10^{6} / 1 \mathrm{ml}$ of cell cultivation media.

\section{Biofilm formation on membranes}

Two biofilms were used, one consisting of $S$. gordonii and $A$. naeslundii representing a biofilm associated with periodontal health ("healthy" biofilm), and another one consisting of all six species representing a periodontopathogenic biofilm ("periodontal" biofilm). Suspensions of the two or six bacterial strains were mixed with nutrient broth (Wilkins Chalgren broth $+5 \%$ sheep blood) in a ratio 1: 19. Then test specimens were dipped first into $25 \%$ serum (Sigma-Aldrich, Buchs, Switzerland) solution and thereafter into CHX0.12, or CHX0.06 for $1 \mathrm{~min}$ before placing into 24-well-plates, and exposing to the bacterial suspension. After an incubation time for $2 \mathrm{~h}$ and 8 $\mathrm{h}$ under anaerobic conditions, biofilms were removed from the surface. After mixing by pipetting, a serial dilution was made and the total cfu counts assessed. Further, in case of the six-species biofilms, the loads of $P$. gingivalis and $T$. forsythia were determined by using realtime PCR [16].

In a second series of experiments, membranes were treated as before, but after an incubation time of $8 \mathrm{~h}$, membranes were exposed again to the respective chlorhexidine digluconate solution or $0.9 \mathrm{w} / \mathrm{v} \mathrm{NaCl}$ (control) for $1 \mathrm{~min}$. Then, the solution was removed and bacterial suspension was added again for $16 \mathrm{~h}$. Thereafter, the procedure was repeated twice per day to simulate clinical rinsing of the oral cavity with chlorhexidine digluconate solution two-times per day. After three days, the bacterial counts were determined as described above.

\section{Adhesion of PDL fibroblasts and gingival epithelial cells (TIGK)}

The membrane specimens were dipped into $25 \%$ serum solution and thereafter into chlorhexidine digluconate solution in three concentrations (CHX0.12, CHX0.06, CHX0.015 (to mimic a possible dilution gradient) or 0.9 $\mathrm{w} / \mathrm{v} \mathrm{NaCl}$ (control)) for $1 \mathrm{~min}$. Afterwards, the specimens were placed in 24-well-plates and PDL fibroblasts or TIGK were added. Membranes were incubated with PDL fibroblasts with $5 \% \mathrm{CO}_{2}$ for $72 \mathrm{~h}$ or with TIGK for $24 \mathrm{~h}$ (each about $10^{5}$ cells $/ \mathrm{mm}^{2}$ ), before the numbers of adherent fibroblasts were counted.

\section{Influence of microorganisms on adhesion of PDL fibroblasts and TIGK}

Experiments with PDL fibroblasts and TIGK cells were repeated in the presence of bacterial lysates. Bacterial suspensions of two or six species were prepared as described before and adjusted to the concentrations $10^{7} /$ $\mathrm{ml}, 10^{8} / \mathrm{ml}$, and $10^{9} / \mathrm{ml}$. Then the suspensions had been exposed to ultrasonication of $160 \mathrm{~W}$ for $10 \mathrm{~min}$, and filtered through membranes with a pore size of $400 \mu \mathrm{m}$. The through-flow or $0.9 \% \mathrm{w} / \mathrm{v} \mathrm{NaCl}$ was finally added to the cell culture medium in a ratio 1: 9 .

Finally, one concentration of bacteria $\left(10^{7} / \mathrm{ml}\right)$ and chlorhexidine digluconate solution (CHX0.015) were selected to study a potential interference of both components. Treatment of barrier membranes and the other processing steps were made as described above.

\section{Expression of IL-8 and TGF $\beta 1$ in PDL fibroblasts}

Moreover, the potential effects of $\mathrm{CHX}$ and bacterial lysates on PDL fibroblasts, which are critical for gingival wound healing, were analyzed at gene expression level. Membranes were dipped before adding PDL fibroblasts into CHX0.015 or lysates of bacterial suspensions $\left(10^{8}\right.$ $/ \mathrm{ml}$ ) were added. After the treatment of cells, RNA was extracted by using the innuPREP RNA Mini Kit (Analytic Jena, Jena, Germany) and cDNA generated from 100 ng total RNA by using the GoScript ${ }^{\text {Tit }}$ Reverse Transcription System (Promega, Madison, WI, USA) according to the manufacturers' instructions. Thereafter realtime PCR using GoTaq ${ }^{\circ}$ qPCR Master Mix (Promega) with respective primers was used to quantify mRNA expression of IL- 8 and TGF $\beta 1$. The primers for IL-8 (primer: fwd: 5'-CACTGCGCCAACACAGAAAT-3', rev.: 5'-TGGCCCTTGGCCTCAATTTT-3'; \# BC013615.1) and TGF $\beta 1$ (primer: fwd.: 5'-CCAGATCCTGTCCA AGCTGC-3'; rev.: 5' -GCTGAGGTATCGCCAGGAAT3'; \# NM_000660.6) were designed by using PRIMERBLAST being a tool for finding specific primers (National Center for Biotechnology Information, U.S. National Library of Medicine, Bethseda, USA). GADPH [17] served as the reference gene. 


\section{Statistical analysis}

All experiments were performed in independent quadruplicates in at least two series. Statistical analyses based on $\log 10$ of bacterial counts (total colony forming units (CFU) and counts of selected periodontopathogens) as well as on the number of attached cells / $\mathrm{mm}^{2}$.

Parameter-free tests were applied for statistical analysis. After performing Kruskal-Wallis-H-test for comparing all groups, Mann-Whitney-U-test determined differences to the control each. Only for analyzing mRNA expression, Student t-test was used. The level of significance was set to $p=0.05$. Software
SPSS 24.0 (IBM SPSS Statistics, Chicago, IL, USA) was used.

\section{Results}

$\mathrm{CHX}$ before biofilm formation

Without exposing to CHX, in median $5.11 \log 10 \mathrm{cfu}$ and $5.59 \log 10 \mathrm{cfu}$ were counted in "healthy" biofilms on polylactide membrane after $2 \mathrm{~h}$ and $8 \mathrm{~h}$, the respective number for the collagen membrane was $5.02 \log 10$ after $2 \mathrm{~h}$ and $5.68 \log 10 \mathrm{cfu}$ after $8 \mathrm{~h}$. The differences between the two membranes were not statistically significant. $\mathrm{CHX}$ solutions did not remarkly influence the cfu counts on the polylactide membrane, cfu counts were reduced

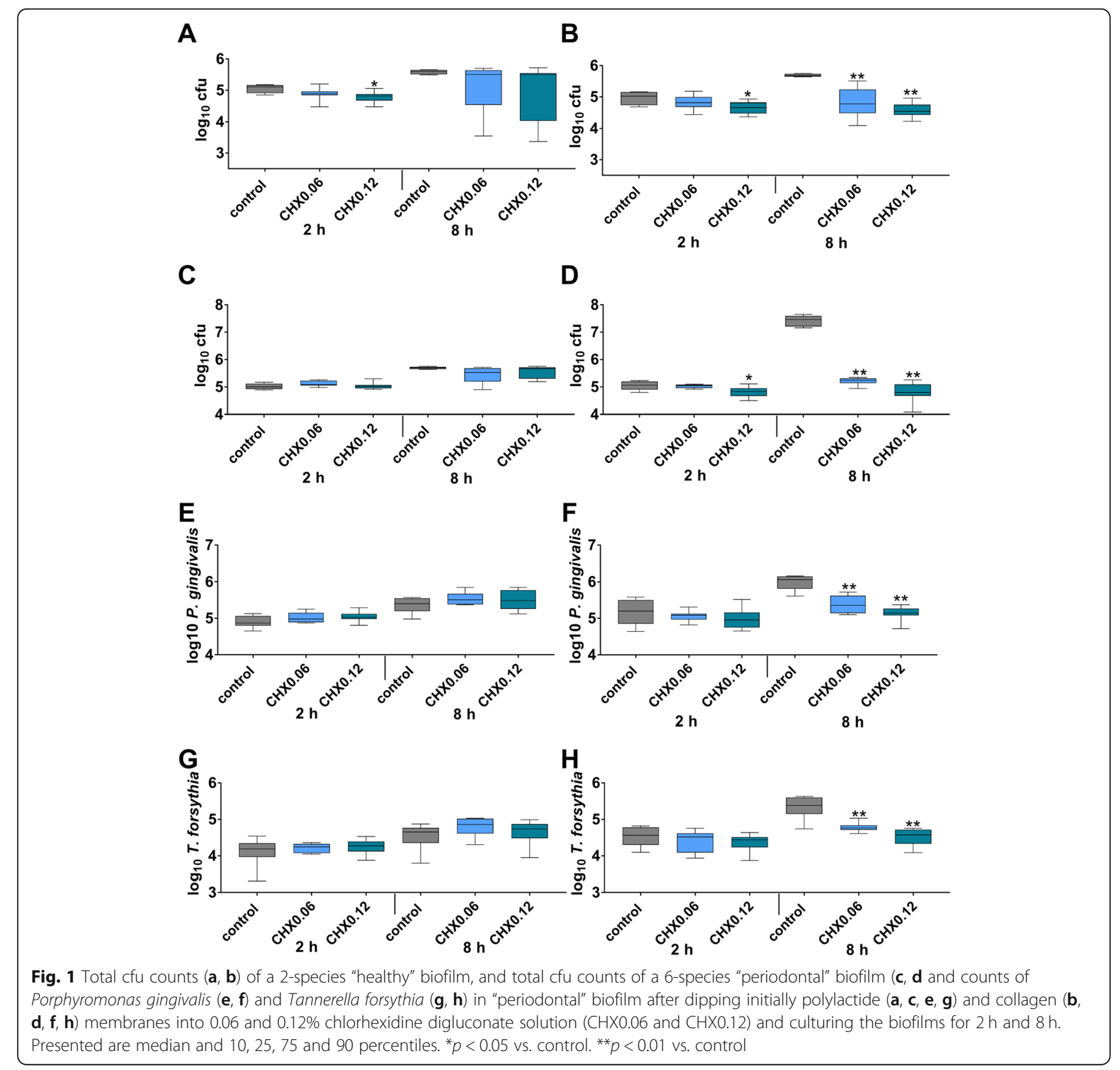


only by $0.09 \log 10$ in median $8 \mathrm{~h}$ after dipping the membrane into CHX0.12 (Fig. 1a). On the collagen membrane, CHX0.06 and CHX0.12 reduced the cfu counts of the "healthy" biofilm by $1.13 \log 10$ after $8 \mathrm{~h}$ of biofilm formation (each $p=0.001$; Fig. 1b).

Without exposing to $\mathrm{CHX}$ in median $5.01 \log 10 \mathrm{cfu}$ and $5.70 \log 10 \mathrm{cfu}$ were counted in "periodontal" biofilms on polylactide membrane after $2 \mathrm{~h}$ and $8 \mathrm{~h}$, the respective number for the collagen membrane was 5.06 $\log 10$ after $2 \mathrm{~h}$ and $7.46 \log 10 \mathrm{cfu}$ after $8 \mathrm{~h}$. The difference between the two membranes was statistically significant at $8 \mathrm{~h} \quad(p<0.001)$. And there was also a statistically significant difference between "healthy" and "periodontal" biofilms on polylactide and collagen membranes each after $8 \mathrm{~h}(p=0.016 ; p=0.004)$. CHX did not remarkly influence the cfu counts on the polylactide membrane (Fig. 1c). On the collagen membrane, the CHX0.12 reduced the cfu counts of the "periodontal" biofilm by $2.22 \log 10$ and by $2.66 \log 10$ cfu when membranes were exposed initially to CHX0.06 and CHX0.12 (each $p=0.001$; Fig. 1d).

Determination of selected periodontopathogens by real-time PCR counts not only bacteria being able to form colony forming units. The numbers include also metabolically inactive and in part dead bacteria. Following, the results are not totally comparable to those obtained by culturing. Within the "periodontal" biofilms and without CHX exposure, counts of $P$. gingivalis and $T$. forsythia were higher on the collagen membrane than on the polylactide one at $8 \mathrm{~h}(p<0.001 ; p=0.001)$. CHX did influence neither the $P$. gingivalis counts nor the $T$. forsythia counts on the polylactide membrane (Fig. 1e, g). On the collagen membrane, less $P$. gingivalis were counted after exposing membrane to CHX (CHX0.06, CHX0.12 both $\mathrm{p}<0.001$ ) at $8 \mathrm{~h}$ of biofilm formation (Fig. 1f). Also less T. forsythia were counted after exposing the collagen membrane to CHX (CHX0.06 $p=0.006$, CHX0.12 $p<0.001$ ) at $8 \mathrm{~h}$ of biofilm formation (Fig. 1h).

\section{More-fold CHX rinsing in biofilm formation}

Without exposing to $\mathrm{CHX}$, in median $7.28 \log 10 \mathrm{cfu}$ were counted in "healthy" biofilms on polylactide membrane at $3 \mathrm{~d}$, the respective number for the collagen membrane was $7.56 \log 10$. The difference between the two membranes was statistically significant $(p=0.038)$. CHX0.06 and CHX 0.12 reduced the cfu counts by 3.52 $\log 10$ and $5.97 \log 10$ (each $p<0.001$ ) on the polylactide membrane (Fig. 2a). On the collagen membrane (Fig. 2b), the decrease was $4.05 \log 10 \mathrm{cfu}(\mathrm{CHX} 0.06 ; p<0.001)$ and $6.26 \log 10 \mathrm{cfu}(\mathrm{CHX} 0.12 ; \mathrm{p}<0.001)$.

Without exposing the membrane to CHX in median $7.24 \log 10 \mathrm{cfu}$ were counted in "periodontal" biofilms on polylactide membrane at $3 \mathrm{~d}$, the respective number for the collagen membrane was $7.53 \log 10$. The difference between the two membranes was statistically significant $(p=0.001)$. However, there was no difference of total bacterial counts between the "healthy" biofilm and the "periodontal" biofilm neither on polylactide nor on collagen membranes. CHX0.06 reduced the cfu counts of "periodontal" biofilms by $2.86 \log 10$ on the polylactide (Fig. 2c) and by 4.28 on the collagen (Fig. 2d) membranes (each $p<0.001$ ). After morefold applying CHX 0.12 in median no cfu was counted on both membranes.

Within the "periodontal" biofilms and without CHX exposure, counts of $P$. gingivalis and T. forsythia were higher on the collagen membrane than on the polylactide membrane at $3 \mathrm{~d}(p=0.015 ; p=0.021)$. CHX0.06 and CHX0.12 reduced the $P$. gingivalis counts on polylactide (Fig. 2e) and collagen (Fig. 2f) membranes (each $p<0.001)$. CHX0.12 also reduced T. forsythia counts on the polylactide membrane $(p=0.001$; Fig. $2 \mathrm{~g})$. On the collagen membrane, both $\mathrm{CHX}$ were active against $T$. forsythia (each $p<0.001$; Fig. 2h).

\section{Adhesion of PDL fibroblasts and TIGK}

Without exposing to $\mathrm{CHX}$ in median 16.5 PDL fibroblasts $/ \mathrm{mm}^{2}$ were counted on the polylactide membrane after 3 $\mathrm{d}$, the respective number for the collagen membrane was 63.0 PDL fibroblasts $/ \mathrm{mm}^{2}$. The difference between the two membranes was statistically significant $(p<0.001)$. Applying CHX0.015 to the polylactide membrane did not change the number of attached PDL fibroblasts, but CHX0.06 and CHX0.12 reduced these numbers on membranes ( $p=0.004, p=0.005$; Fig. 3a). On collagen membranes, there was a decrease of attached cells after applying any $\mathrm{CHX}$ vs. control (each $\mathrm{p}<0.001$; Fig. 3b).

Without exposing to CHX, in median 15.5 TIGK cells $/ \mathrm{mm}^{2}$ were counted on the polylactide membrane after $24 \mathrm{~h}$, the respective number for the collagen membrane was 89.0 cells $/ \mathrm{mm}^{2}$. The difference between the two membranes was statistically significant $(p<0.001)$. Applying $\mathrm{CHX}$ initially to membranes did not change statistically significantly the number of attached TIGK cells on polylactid membranes (Fig. 3c). On collagen membrane, there was a decrease of attached cells vs. control after applying any CHX ( $<<0.001$; Fig. 3d).

\section{Lysates of microorganisms and adhesion of PDL fibroblasts and gingival epithelial cells to membranes}

Lysates of the two bacterial species being associated with periodontal health did not change attachment of PDL fibroblasts to the polylactide membrane (Fig. 5a). On the collagen membrane, there were more attached PDL fibroblasts in part (lysates from $10^{7}$ bacteria $/ \mathrm{ml}: p=0.021$ and $10^{8}$ bacteria/ml: $\left.\mathrm{p}<0.001\right)$. However, when combined with CHX0.015, the number of attached PDL fibroblasts decreased when compared to control $(p<$ 0.001; Fig. 4b). 
A

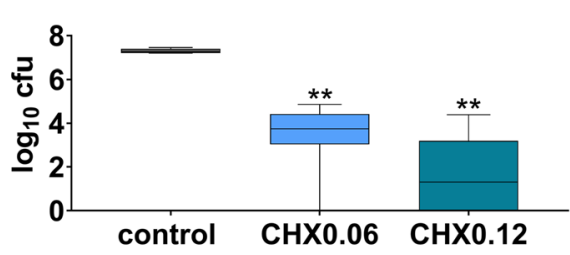

C

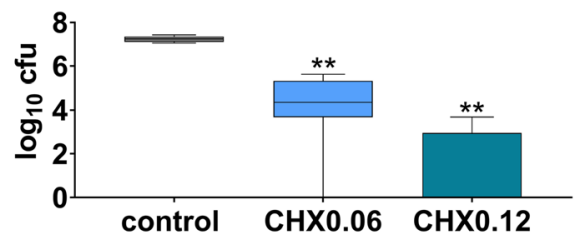

B

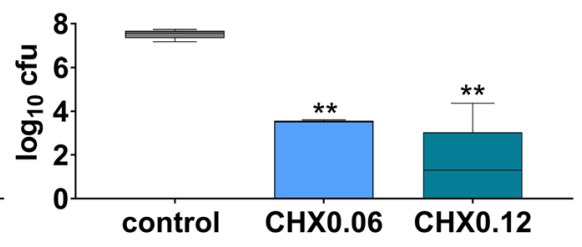

D

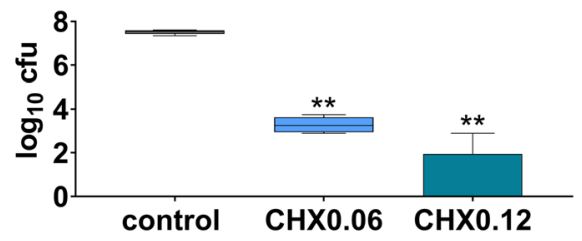

E

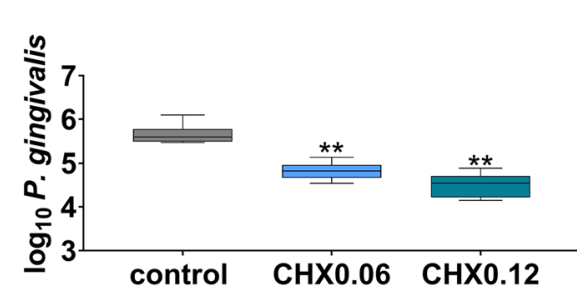

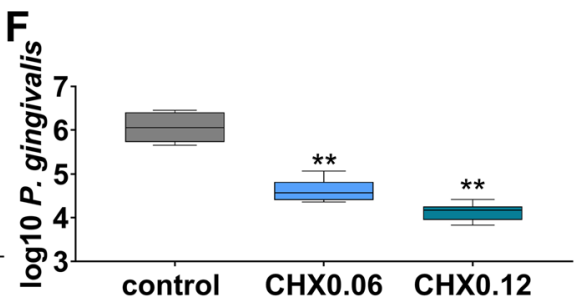
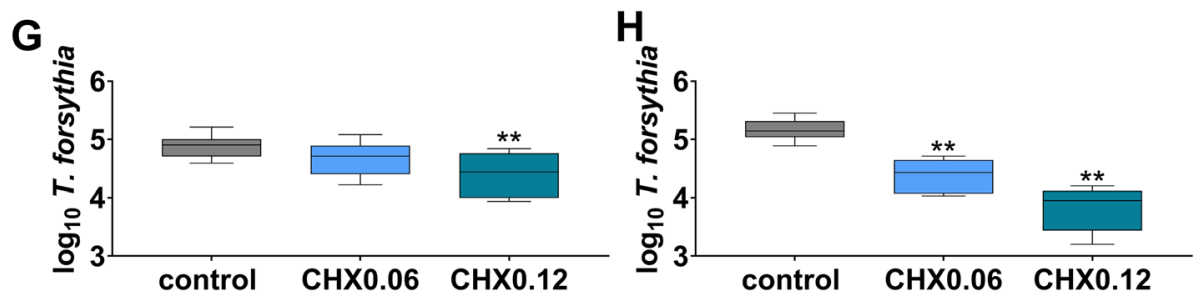

Fig. 2 Total cfu counts (a, $\mathbf{b})$ of a 2-species "healthy" biofilm, and total cfu counts of a 6-species "periodontal" biofilm (c, $\mathbf{d}$ and counts of Porphyromonas gingivalis $(\mathbf{e}, \mathbf{f})$ and Tannerella forsythia $(\mathbf{g}, \mathbf{h})$ in "periodontal" biofilm after more-fold dipping of polylactide $(\mathbf{a}, \mathbf{c}, \mathbf{e}, \mathbf{g})$ and collagen ( $\mathbf{b}, \mathbf{d}, \mathbf{f}, \mathbf{h}$ ) membranes into 0.06 and $0.12 \%$ chlorhexidine digluconate solution (CHX0.06 and CHX0.12) and culturing biofilms for $3 \mathrm{~d}$. Presented are median and 10,25, 75 and 90 percentiles. ${ }^{* *} p<0.01$ vs. control

Lysates of the six bacterial species being associated with periodontal disease decreased further the low number of attached PDL fibroblasts to the polylactide membrane (lysates from $10^{8}$ bacteria/ml: $p=0.039$ and $10^{9}$ bacteria/ml: $p=0.004$; Fig. $4 \mathrm{c}$ ). On the collagen membrane, there were also less attached PDL fibroblasts when lysates from $10^{9}$ bacteria/ml were added $(p=$ 0.032; Fig. 4d). When bacterial lysates were added to membranes dipped before into $\mathrm{CHX} 0.015$; the number of attached PDL fibroblasts was lower when compared to control (polylactide membrane: $p=0.003$, collagen membrane: $\mathrm{p}=0.004)$.

Lysates of the two bacterial species being associated with periodontal health and lysates of the six bacterial species being associated with periodontal disease did not change attachment of TIGK to the polylactide membrane (Fig. 4e; g). On collagen, both lysates decreased the number of attached TIGK cells $(p=0.031-p<$ 0.001; Fig. 4f, h).

When bacterial lysates were added to the collagen membrane dipped before into $\mathrm{CHX} 0.015$; the numbers of attached TIGK cells were lower when compared to control (2-species: $\mathrm{p}<0.001,6$-species: $p=0.018$ ).

\section{Expression of IL-8 and TGF $\beta 1$ in PDL fibroblasts}

Due to the low number of attached PDL fibroblasts on the polylactide membrane, amount of extracted RNA was insufficient to determine expression of cytokines. 

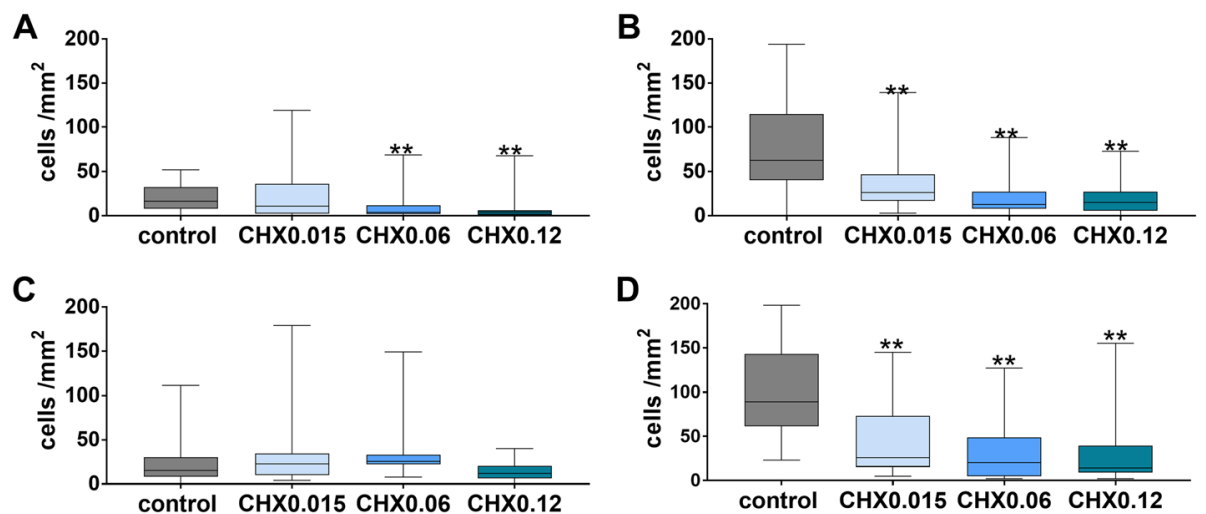

Fig. 3 Attached PDL fibroblasts ( $\mathbf{a}, \mathbf{b}$; after $72 \mathrm{~h}$ of incubation) and TIGK (c, d; after $24 \mathrm{~h}$ of incubation) to polylactide (a, $\mathbf{c}$ ) and collagen (b, d) membranes after dipping initially membranes into $0.015,0.06$ and $0.12 \%$ chlorhexidine digluconate solution (CHX0.015, CHX0.06 and CHX0.12; a c). Presented are median and 10,25, 75 and 90 percentiles. ${ }^{* *} p<0.01$ vs. control

Following, only results on collagen membrane can be presented. CHX0.015 provoked an increase of IL-8 expression in PDL fibroblasts $(p=0.014)$. There was also a tendency to higher expression of IL-8 in the presence of bacterial lysates of "periodontal biofilm" without reaching statistical significance $(p=0.062)$. TGF $\beta 1$-expression did not differ significantly between membranes with and without exposure to $\mathrm{CHX} 0.015$ or bacterial lysates (Fig. 5).

\section{Discussion}

The present in-vitro study has evaluated the effect of chlorhexidine digluconate on bacterial contamination and adhesion of epithelial cells and PDL fibroblasts to two commercially available membranes. The results revealed an inhibition of bacterial adhesion to membranes by chlorhexidine digluconate. However, there were also clear differences between the two membranes, not only regarding the activity of chlorhexidine, but also regarding the attachment of host cells and bacterial biofilm formation.

Three major types of membranes are commercially available, non resorbable (PTFE-based, or e-PTFEbased), resorbable tissue-derived collagen membranes and resorbable polyester (polyglycolic acid, polylactid acid, poly-e-caprolactone) membranes [18]. In vitro studies have shown a higher bacterial adhesion on collagen membrane than on e-PTFE- and PTFE- based membranes [11], or glycolide fiber membrane [19]. The limited attachment on the polyester membrane is discussed in the light of a hydrophobicity of the material [19]. Our results confirm the higher bacterial adhesion on collagen-based membrane when compared with polylactide-based membrane but only when a bacterial mixture consisting of periodontopathogens was used. Bacterial species being associated with periodontal health colonized the polylactide membrane and the collagen membrane similarily.

One of the main functions of GTR membranes is to inhibit epithelial down-growth. In particular, if the membrane is exposed to the oral cavity an epithelial seal may prevent colonization of bacteria at the deeper parts of the membranes. The GTR membrane should function also as a substrate for the migration of cells for wound healing and regeneration [20]. Not only bacteria, but also the oral epithelial cells and periodontal ligament fibroblasts should preferably attach to the membrane. Previous studies have confirmed the preference of host cells to collagen membrane thus resulting in better adhesion of PDL fibroblasts than on glycolide fiber membrane [21] and ePTFE-membrane [10, 21].

In the present study, released compounds of bacteria being associated with periodontal health did not negatively influence attachment of PDL fibroblasts to membranes. In contrast, there was a negative influence of products by bacteria being associated with periodontal disease. Bacteria being associated with periodontal disease use collagen as a nutrient source $[22,23]$ and moreover it was shown that proteolytic enzymes of $P$. gingivalis can degrade collagen membranes [24]. But also a cleavage of host cell receptors on membranes and of cell adhesion molecules enabling the contact between the cells can be suggested. E.g., P. gingivalis proteases affect cell adhesion capability of fibronectin and tenascin $\mathrm{C}$ to fibroblasts [25] and they are able to degrade adhesion molecules essential for epithelial integrity [26].

In a clinical study the presence of $P$. gingivalis at the time-point of surgery was found to be negatively associated with the outcome, the attachment gain was $1.5 \mathrm{~mm}$ less when compared with no presence [9]. This underlines the need to eliminate or at least to reduce periodontopathogenic bacteria before regenerative periodontal surgery using membranes. 
A

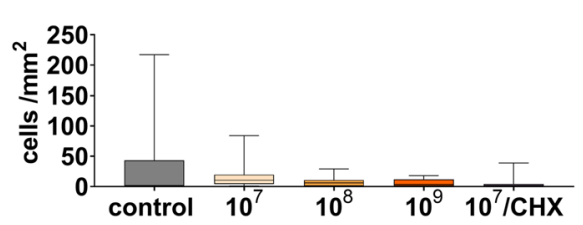

c

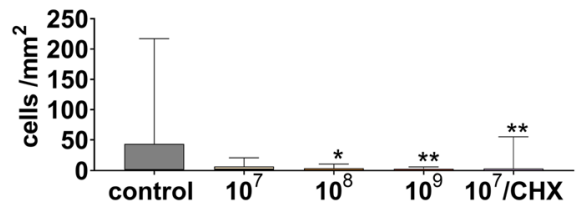

B

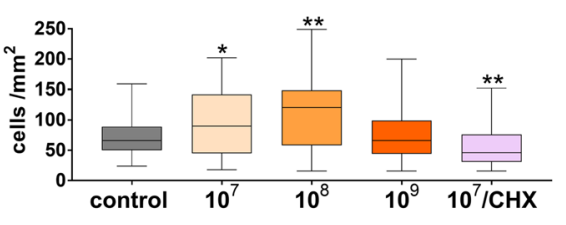

D

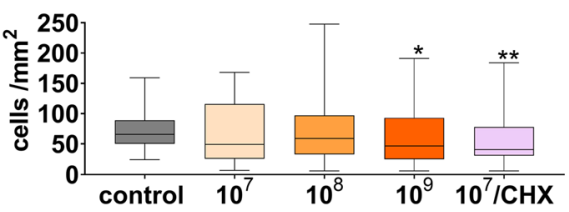

$\mathbf{F}$

E

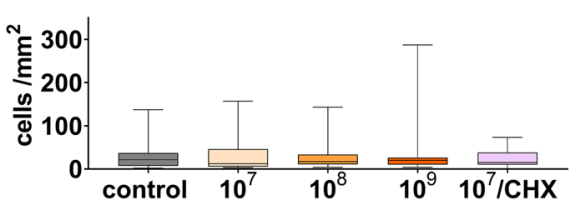

G

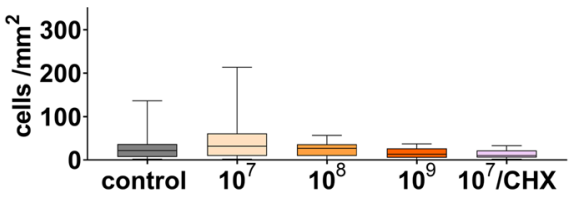

H

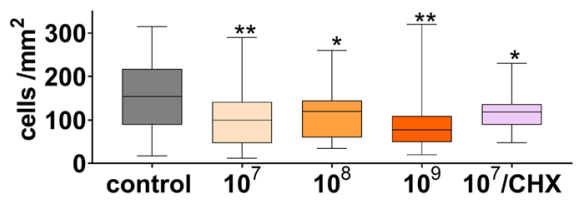

Fig. 4 Attached PDL fibroblasts (a, b, $\mathbf{c}, \mathbf{d}$; after $72 \mathrm{~h}$ of incubation) and TIGK (e, $\mathbf{f}, \mathbf{g}, \mathbf{h}$; after $24 \mathrm{~h}$ of incubation) to polylactide (a, $\mathbf{c}, \mathbf{e}, \mathbf{g})$ and collagen $(\mathbf{b}, \mathbf{d}, \mathbf{f}, \mathbf{h})$ membranes in the presence bacterial lysates (prepared from two species being associated with periodontal health $(\mathbf{a}, \mathbf{b}, \mathbf{e}, \mathbf{f})$ or six species associated with periodontal disease $(\mathbf{c}, \mathbf{d}, \mathbf{g}, \mathbf{h})$ in three concentrations and in part after dipping initially membranes into $0.015 \%$ digluconate solution $(\mathrm{CHX}){ }^{*} p<0.05$ vs. control. Presented are median and 10, 25, 75 and 90 percentiles. ${ }^{* *} p<0.01$ vs. control

This in-vitro study mimicked an exposure of the membrane to the oral cavity which happens quite frequently after periodontal surgery. Data from the literature report a frequency of $44 \%$ [27] up to $87 \%$ [28]. The high frequency of membrane exposure and the resulting problem of bacterial colonization underline the need to search for options to inhibit biofilm formation on membranes. One possibility is the modification of the membrane itself. Loading of an electrospun poly( $\varepsilon$ caprolactone)-gelatin nanofiber membrane with metronidazole showed favourable results in vitro and in animal model [29]. In vitro, also the addition of amoxicillin or tetracycline inhibited the adhesion of A. actinomycetemcomitans or Streptococcus mutans [19]. Further, silver nanoparticles incorporated in a membrane inhibited adhesion of periodontopathogenic bacteria [30]. However, the available clinical studies report different outcomes. A collagen membrane with added metronidazole did not show a superiority to a membrane without [31]. Using a membrane loaded with $25 \%$ doxycycline resulting in more probing depth reduction than using one without antibiotic [32].

The second approach is the adjunctive application of antimicrobials, either topically or systemically. Regarding the systemic use of antimicrobials, the data are very limited. A study applying minocycline before surgery and thereafter amoxicillin and doxycycline has failed to show any benefit by the antibiotics [33]. At present, rinsing 

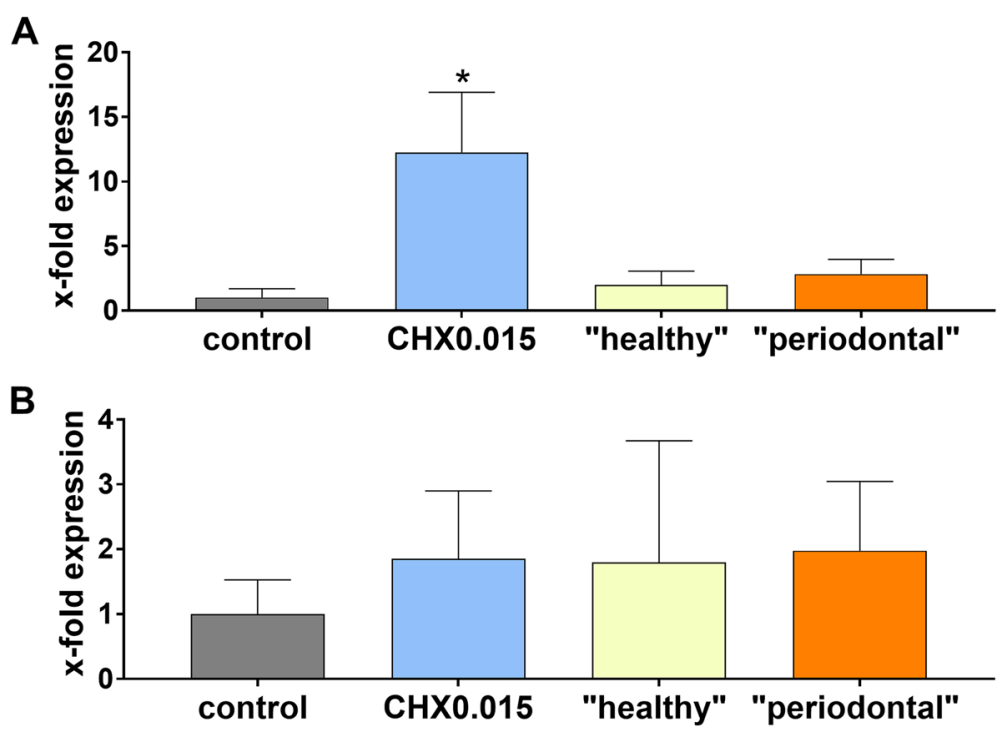

Fig. 5 mRNA expression of IL-8 (a) and TGFß1 (b) of PDL fibroblasts on collagen membranes after dipping into $0.15 \%$ CHX solution and in the presence of bacterial lysates being associated with periodontal health and periodontal disease. Presented are means and SD related to expression on collagen membranes without $\mathrm{CHX}$ and bacterial lysates. ${ }^{*} p<0.05$ vs. control

with chlorhexidine digluconate two-times per day is recommended after GTR surgery [4].

In the present study the additional application of $\mathrm{CHX}$ was investigated. The starting point were two commonly used CHX concentrations in the mouthrinses, 0.06 and $0.12 \%$. No commercially available product was included. However, it cannot be excluded that additives in the CHX formulations may interfere with its activity [34].

The first experiments mimicked a one-time exposure of the membrane to CHX. This may simulate a clinical situation at the time of surgery. The initial dipping into CHX decreased bacterial counts and those of $P$. gingivalis and T. forsythia on the collagen membrane, the antiadhesive activity was higher when CHX0.12 was was used in comparison with CHX0.06. The colonization of the polylactide membrane was not influenced by dipping into any $\mathrm{CHX}$ solution. Chlorhexidine digluconate is a cationic molecules which is attaching to negatively charged surfaces [35], when attached it has a high substantivity [36] meaning a long lasting post-antimicrobial activity. Further, the collagen membrane is hydrophilic [19] and the polylactide membrane is rather hydrophobic [37], which may play a role both in bacterial adhesion as well as in the attachment of CHX.

The second series of experiments mimicked the clinical situation of membrane exposure where CHX is applied twice per day. The dipping of the membranes twotimes per day for three days decreased remarkably bacterial colonization of both bacterial species being associated with periodontal health and of those being associated with periodontal disease. Again the antiadhesive activity was higher on the collagen membrane than on polylactide membrane, but in contrast to the onetime dipping a reduction of the bacterial adhesion was seen on both membranes.

Also the effect of the CHX on adhesion of PDL fibroblasts and gingival epithelial cells was investigated. A lower concentration than the commercially ones was included as it can be expected that the concentration of chlorhexidine is lowered in deeper regions when contacting the membrane. Dipping the collagen membrane in this low concentrated CHX $(0.015 \%)$ already decreased the numbers of attached PDL fibroblasts and increased expression of the pro-inflammatory cytokine IL-8. The negative effect of CHX on the attachment of PDL fibroblasts and epithelial cells on collagen membrane was concentration dependent. Meanwhile cytotoxicity of chlorhexidine was reported in many studies. Only short-time exposure of primary human fibroblasts to commercially available concentrations of chlorhexidine gluconate and digluconate affects extremely their viability $[34,38]$, in a scratching assay no defect closure was seen after $3 \mathrm{~min}$ of $0.002 \%$ chlorhexidine gluconate [38]. The inhibition of attachment of oral cells to membranes by $\mathrm{CHX}$ contradicts the positive effect in inihibiting bacterial adhesion and underlines that membranes should not be dipped into CHX before placement during surgery.

\section{Conclusions}

In summary, the polylactide membrane may be a treatment option for patients who reject medical devices derived from animals. Bacterial colonization seems to be more limited compared to a collagen-based membrane. However, this 
obvious advantage has to be seen in contrast with the relatively low attachment of gingival epithelial cells and periodontal ligament fibroblasts.

The in-vitro results of this study suggest using membranes in guided tissue regeneration only when bacteria being associated with periodontal disease have been elimiated. An exposure of the membrane should be avoided. Rinsing with CHX may prevent or at least retard bacterial colonization on membranes being exposed in the oral activity. However, a certain negative effect on wound healing cannot be excluded.

\section{Abbreviations \\ Cfu: Colony forming unit; CHX: Chlorhexidine digluconate solution(s); CHX0.015: 0.015\% chlorhexidine digluconate solution; CHX0.06: 0.06\% chlorhexidine digluconate solution; CHX0.12: 0.12\% chlorhexidine digluconate solution; GTR: Guided tissue regeneration; IL-8: Interleukin-8; PDL: Periodontal ligament; TGF- $\beta 1$ : Transforming growth factor $\beta 1$; TIGK: Telomerase-inactivated gingival keratinocytes}

\section{Acknowledgements}

The authors are very grateful to Anna Magdoń for her excellent laboratory work.

\section{Authors' contributions}

SE and AS designed the study. JLR and CM performed the experiments and collected the data. JLR, CM, and SE analyzed the data. All authors (JLR, CM, AS, and SE) wrote the paper and have read and approved the manuscript.

\section{Funding}

The study was funded by Sunstar Suisse SA, Etoy, Switzerland. The funder had no role in study design, data collection and analysis, decision to publish and preparation of the manuscript.

\section{Availability of data and materials}

The datasets used and/or analyzed during the current study available from the corresponding author on reasonable request.

\section{Ethics approval and consent to participate}

The procedure was in accordance with the approved guidelines and regulations of the local ethics committee of the University of Bern (Kantonale Ethikkommission: KEK). Human PDL fibroblasts were collected from periodontally healthy patients during regular orthodontic treatment unrelated to the study and thereafter irreversibly anonymized. Patients signed an informed consent for using the biological material for research purposes. For this procedure (consent of patient, using irreversible anonymized biological material obtained as "waste" during regular clinical therapy) no special previous ethical approval from the KEK was necessary.

\section{Consent for publication}

Not applicable.

\section{Competing interests}

The authors (JLR, CM) declare that they have no competing interests. Anton Sculean is section editor and Sigrun Eick is associate editor of BMC Oral Health. The authors alone are responsible for the content and writing of the paper.

\section{Author details}

'Department of Periodontology, School of Dental Medicine, University of Bern, Bern, Switzerland. 'Department of Restorative, Preventive and Pediatric Dentistry, School of Dental Medicine, University of Bern, Bern, Switzerland.
Received: 2 September 2019 Accepted: 29 November 2019

Published online: 26 December 2019

\section{References}

1. Bottino MC, Thomas V. Membranes for periodontal regeneration--a materials perspective. Front Oral Biol. 2015;17:90-100.

2. Vignoletti F, Nunez J, Sanz M. Soft tissue wound healing at teeth, dental implants and the edentulous ridge when using barrier membranes, growth and differentiation factors and soft tissue substitutes. J Clin Periodontol. 2014;41(Suppl 15):S23-35.

3. Stoecklin-Wasmer C, Rutjes AW, da Costa BR, Salvi GE, Juni P, Sculean A. Absorbable collagen membranes for periodontal regeneration: a systematic review. J Dent Res. 2013:92:773-81.

4. Cortellini P, Tonetti MS. Focus on intrabony defects: guided tissue regeneration. Periodontol 2000. 2000;22:104-32.

5. Needleman IG, Worthington HV, Giedrys-Leeper E, Tucker RJ. Guided tissue regeneration for periodontal infra-bony defects. Cochrane Database Syst Rev. 2006;(2):CD001724. Published 2006 Apr 19. https://doi.org/10.1002/ 14651858.CD001724.pub2.

6. Cortellini P, Tonetti MS. Clinical performance of a regenerative strategy for intrabony defects: scientific evidence and clinical experience. J Periodontol. 2005;76:341-50.

7. Chen YT, Wang HL, Lopatin DE, O'Neal R, MacNeil RL. Bacterial adherence to guided tissue regeneration barrier membranes exposed to the oral environment. J Periodontol. 1997;68:172-9.

8. Ling LJ, Hung SL, Lee CF, Chen YT, Wu KM. The influence of membrane exposure on the outcomes of guided tissue regeneration: clinical and microbiological aspects. J Periodontal Res. 2003;38:57-63.

9. Nowzari H, MacDonald ES, Flynn J, London RM, Morrison JL, Slots J. The dynamics of microbial colonization of barrier membranes for guided tissue regeneration. J Periodontol. 1996;67:694-702.

10. Chen YT, Hung SL, Lin LW, Chi LY, Ling LJ. Attachment of periodontal ligament cells to chlorhexidine-loaded guided tissue regeneration membranes. J Periodontol. 2003;74:1652-9.

11. Sela MN, Steinberg D, Klinger A, Krausz AA, Kohavi D. Adherence of periodontopathic bacteria to bioabsorbable and non-absorbable barrier membranes in vitro. Clin Oral Implants Res. 1999;10:445-52.

12. Reddy MS, Jeffcoat MK, Geurs NC, Palcanis KG, Weatherford TW, Traxler BM, Finkelman RD. Efficacy of controlled-release subgingival chlorhexidine to enhance periodontal regeneration. J Periodontol. 2003;74:411-9.

13. Zucchelli G, Pollini F, Clauser C, De Sanctis M. The effect of chlorhexidine mouthrinses on early bacterial colonization of guided tissue regeneration membranes. An in vivo study. J Periodontol. 2000;71:263-71.

14. Simion M, Trisi P, Maglione M, Piattelli A. Bacterial penetration in vitro through GTAM membrane with and without topical chlorhexidine application. A light and scanning electron microscopic study. J Clin Periodontol. 1995;22:321-31.

15. Moffatt-Jauregui CE, Robinson B, de Moya AV, Brockman RD, Roman AV, Cash MN, Culp DJ, Lamont RJ. Establishment and characterization of a telomerase immortalized human gingival epithelial cell line. J Periodontal Res. 2013;48:713-21.

16. Eick S, Straube A, Guentsch A, Pfister W, Jentsch H. Comparison of real-time polymerase chain reaction and DNA-strip technology in microbiological evaluation of periodontitis treatment. Diagn Microbiol Infect Dis. 2011;69:12-20.

17. Shen Y, Li Y, Ye F, Wang F, Lu W, Xie X. Identification of suitable reference genes for measurement of gene expression in human cervical tissues. Anal Biochem. 2010;405:224-9.

18. Bottino MC, Thomas V, Schmidt G, Vohra YK, Chu TM, Kowolik MJ, Janowski GM. Recent advances in the development of GTR/GBR membranes for periodontal regeneration--a materials perspective. Dent Mater. 2012;28:703-21.

19. Cheng CF, Wu KM, Chen YT, Hung SL. Bacterial adhesion to antibiotic loaded guided tissue regeneration membranes - a scanning electron microscopy study. J Formos Med Assoc. 2015;114:35-45.

20. Behring J, Junker R, Walboomers XF, Chessnut B, Jansen JA. Toward guided tissue and bone regeneration: morphology, attachment, proliferation, and migration of cells cultured on collagen barrier membranes. A systematic review. Odontology. 2008;96:1-11.

21. Hung SL, Lin YW, Wang YH, Chen YT, Su CY, Ling L. Permeability of Streptococcus mutans and Actinobacillus actinomycetemcomitans through 
guided tissue regeneration membranes and their effects on attachment of periodontal ligament cells. J Periodontol. 2002;73:843-51.

22. Bedi GS, Williams T. Purification and characterization of a collagen-degrading protease from Porphyromonas gingivalis. J Biol Chem. 1994;269:599-606

23. Kawase N, Kishi J, Nakamura H, Hayakawa T. Collagenolytic activity in sonic extracts of Tannerella forsythia. Arch Oral Biol. 2010;55:545-9.

24. Sela MN, Babitski E, Steinberg D, Kohavi D, Rosen G. Degradation of collagen-guided tissue regeneration membranes by proteolytic enzymes of Porphyromonas gingivalis and its inhibition by antibacterial agents. Clin Oral Implants Res. 2009;20:496-502.

25. Ruggiero S, Cosgarea R, Potempa J, Potempa B, Eick S, Chiquet M. Cleavage of extracellular matrix in periodontitis: gingipains differentially affect cell adhesion activities of fibronectin and tenascin-C. Biochim Biophys Acta. 2013;1832:517-26.

26. Eick S, Gadzo N, Tacchi M, Sculean A, Potempa J, Stavropoulos A. Gingipains impair attachment of epithelial cell to dental titanium abutment surfaces. J Biomed Mater Res B Appl Biomater. 2019;107(8):2549-2556. https://doi.org/ 10.1002/jbm.b.34345

27. Sculean A, Donos N, Blaes A, Lauermann M, Reich E, Brecx M. Comparison of enamel matrix proteins and bioabsorbable membranes in the treatment of intrabony periodontal defects. A split-mouth study. J Periodontol. 1999; 70:255-62.

28. Murphy KG. Postoperative healing complications associated with Gore-Tex periodontal material. Part I. incidence and characterization. Int J Periodontics Restorative Dent. 1995;15:363-75.

29. Xue J, Shi R, Niu Y, Gong M, Coates P, Crawford A, Chen D, Tian W, Zhang L. Fabrication of drug-loaded anti-infective guided tissue regeneration membrane with adjustable biodegradation property. Colloids Surf B Biointerfaces. 2015;135:846-54.

30. Rani S, Chandra RV, Reddy AA, Reddy BH, Nagarajan S, Naveen A. Evaluation of the antibacterial effect of silver nanoparticles on guided tissue regeneration membrane colonization--an in vitro study. J Int Acad Periodontol. 2015;17:66-76.

31. Dowell P, al-Arrayed F, Adam S, Moran J. A comparative clinical study: the use of human type I collagen with and without the addition of metronidazole in the GTR method of treatment of periodontal disease. J Clin Periodontol. 1995:22:543-9.

32. Chaturvedi R, Gill AS, Sikri P. Evaluation of the regenerative potential of $25 \%$ doxycycline-loaded biodegradable membrane vs biodegradable membrane alone in the treatment of human periodontal infrabony defects: a clinical and radiological study. Indian J Dent Res. 2008;19:116-23.

33. Minabe M, Kodama T, Kogou T, Fushimi H, Sugiyama T, Takeuchi K, Miterai E, Nishikubo S. Clinical significance of antibiotic therapy in guided tissue regeneration with a resorbable membrane. Periodontal Clin Investig. 2001;23:20-30

34. Eick S, Goltz S, Nietzsche S, Jentsch H, Pfister W. Efficacy of chlorhexidine digluconate-containing formulations and other mouthrinses against periodontopathogenic microorganisms. Quintessence Int. 2011:42:687-700.

35. Koontongkaew S, Jitpukdeebodintra S. Interaction of chlorhexidine with cytoplasmic membranes of Streptococcus mutans GS-5. Caries Res. 1995;29:413-7

36. Nishioka H, Nagahama A, Inoue $Y$, Hagi A. Evaluation of fast-acting bactericidal activity and substantivity of an antiseptic agent, olanexidine gluconate, using an ex vivo skin model. J Med Microbiol. 2018;67:1796-803.

37. Sharma P, Mickel AK, Chogle S, Sharma PN, Han YW, Jones JJ. An evaluation of bacterial contamination of barriers used in periapical tissue regeneration: part 1--bacterial adherence. Quintessence Int. 2008;39:159-63.

38. Liu JX, Werner J, Kirsch T, Zuckerman JD, Virk MS. Cytotoxicity evaluation of chlorhexidine gluconate on human fibroblasts, myoblasts, and osteoblasts. J Bone Jt Infect. 2018;3:165-72.

\section{Publisher's Note}

Springer Nature remains neutral with regard to jurisdictional claims in published maps and institutional affiliations.

Ready to submit your research? Choose BMC and benefit from:

- fast, convenient online submission

- thorough peer review by experienced researchers in your field

- rapid publication on acceptance

- support for research data, including large and complex data types

- gold Open Access which fosters wider collaboration and increased citations

- maximum visibility for your research: over $100 \mathrm{M}$ website views per year

At $\mathrm{BMC}$, research is always in progress.

Learn more biomedcentral.com/submissions 